ERJ

Engineering Research Journal

Faculty of Engineering

Minoufiya University

\title{
EVALUATION OF HARMONIC DETECTION METHODS FOR THREE-PHASE SHUNT ACTIVE POWER FILTER APPLICATIONS
}

\author{
E. E. EL-Kholy A. El-Hefnawy Hamdy M. Mahrous \\ Electrical Engineering Department, Faculty of Engineering, Shebin El-Kom, \\ Minoufiya University, Egypt
}

\begin{abstract}
The shunt active power filter (APF) has proved to be a practical device to eliminate harmonic currents and to compensate reactive power for nonlinear loads. This paper evaluates three different control methods of determining the reference compensating current for a shunt active filter that is working under balanced, unbalanced and distorted source voltages. The methods compared are the instantaneous reactive power theory $(p-q)$, the synchronous reference frame method $(d-q)$ and the proposed method. The simulation results are obtained by with Matlab-Simulink. The shunt (APF) and its control methods have been implemented as a prototype and tested through Digital Signal processor (DSP) showing the good performance of the developed active filter. In balanced sinusoidal source voltages, the differences between the results obtained by the three methods are of minimum importance. For unbalanced and distortion source voltage conditions, the results obtained by the methods referenced are quite different. The proposed control strategy has shown the best choice for all situations studied in this paper.

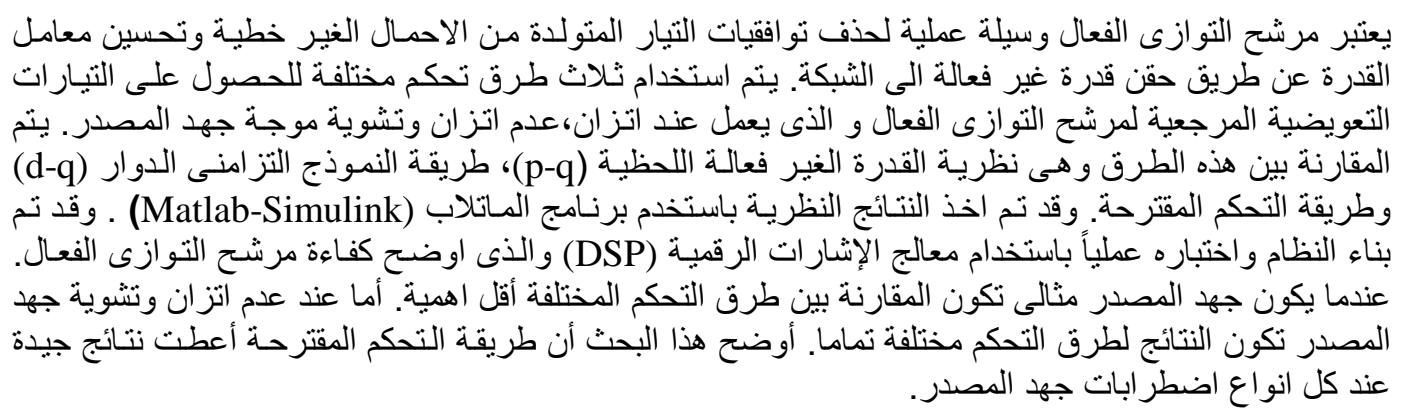

Keywords: Active power filter; $(p-q)$ theory; $d$ - $q$ method; proposed method; reference current extraction; DSP

\section{INTRODUCTION}

In recent years, modern loads typically contain power electronic devices; the current drawn by these modern devices is non-sinusoidal and therefore contains harmonics. Shunt active power filters (APF) were proposed as a means of removing current harmonics. In an active filter, a controller determines the harmonics that are to be eliminated [1]. The output of this controller is the reference of a threephase current control inverter. Fig.1 illustrates the principle of a shunt active power filter.

The nonlinear load is connected to the power system and is supplied by the non-sinusoidal

connected in parallel to the mains, on the point of common coupling PCC, and supplies the current harmonics $i_{c}$ needed to maintain the source current sinusoidal. The control strategy for a shunt active power filter (Fig.2) generates the reference current $i_{c}{ }^{*}$ that must be provided by the power filter to compensate reactive power and harmonic currents demanded by the load. This involves a set of currents in the phase domain, which will be tracked generating the switching signals applied to the electronic converter by means of the appropriate closed-loop switching control technique such as hysteresis current controller. Traditionally active power filters are studied under sinusoidal and symmetrically voltage conditions. This paper compares three control methods Instantaneous Reactive Power $(p-q)$ Theory, Synchronous Reference Frame $(d-q)$ method and proposed method to obtain the reference compensating currents under unbalanced and distortion mains voltage conditions [4]. 


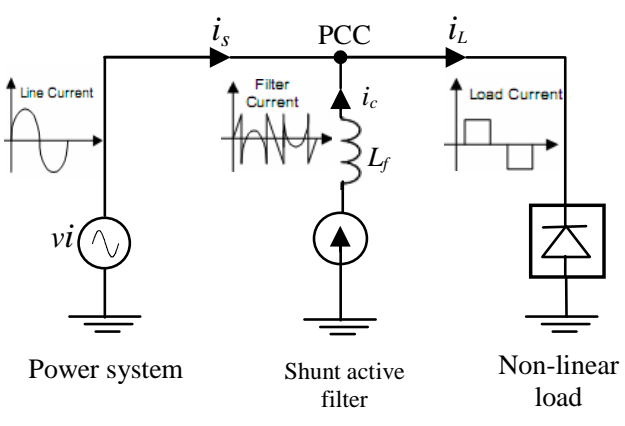

Fig. 1 Principle of a Shunt active filter

\section{ACTIVE POWER FILTER CONTROL METHODS}

Shunt active power filters inject harmonic currents on the network. An outer controller determines the reference harmonic currents that should be injected and thus compensated [2].

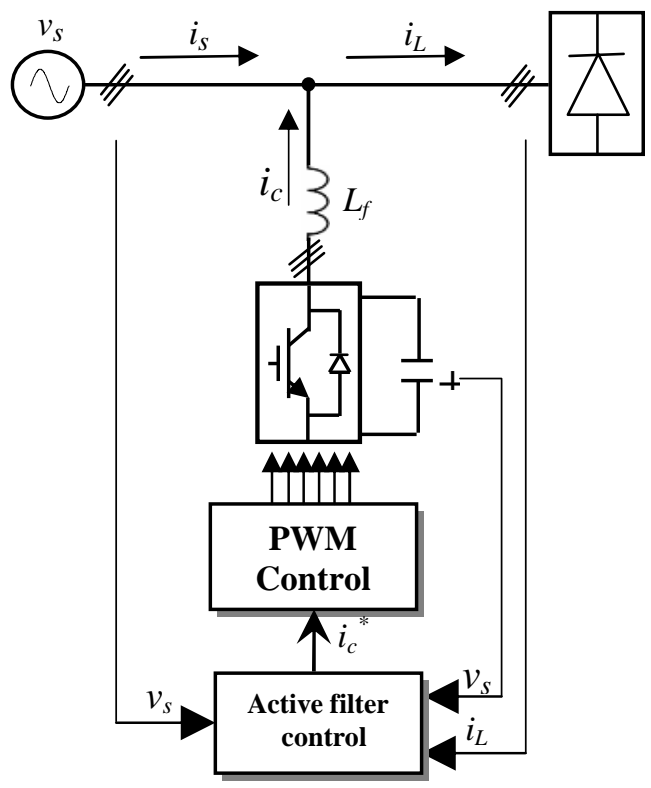

Fig. 2 Basic control of three-phase Shunt active filter

A three phase voltage inverter with current regulation is then used to inject the compensating current into the power line. There are some different methods for implementing the detection of harmonic currents [3], these methods were studied in symmetrical conditions in the literature. The aim of this paper is to qualitatively determine the differences between three of those methods under different conditions of mains voltage.

\subsection{Instantaneous Reactive Power Theory (IRPT)}

Instantaneous Reactive Power Theory (IRPT), also known as the $p-q$ theory [2], [4], [14]. Instantaneous Reactive Power Theory (IRPT) uses the Park Transform, given in Eq.(1), to generate two orthogonal rotating vectors $(\alpha$ and $\beta$ ) from the three phase vectors $(\mathrm{a}, \mathrm{b}$ and $\mathrm{c})$. This transform is applied to the voltage and current and so the symbol $x$ is used to represent $v$ or $i$, when assuming balanced three phase loads the $x_{0}$ term does not use.

$$
\left[\begin{array}{l}
x_{0} \\
x_{a} \\
x_{p}
\end{array}\right]=\sqrt{\frac{2}{3}}\left[\begin{array}{ccc}
\frac{1}{\sqrt{2}} & \frac{1}{\sqrt{2}} & \frac{1}{\sqrt{2}} \\
1 & -\frac{1}{2} & -\frac{1}{2} \\
0 & \frac{\sqrt{3}}{2} & -\frac{\sqrt{3}}{2}
\end{array}\right]\left[\begin{array}{l}
x_{a} \\
x_{b} \\
x_{c}
\end{array}\right]
$$

Fig.3 shows the block diagram for an active power filter based on Instantaneous Reactive Power Theory $(I R P T)$. The supply voltages and load currents are transformed into $\alpha-\beta$ quantities (Eq.1). The instantaneous power of the load consists of a DC (average) component (-) and an oscillating (AC) component $(\sim)$. The instantaneous active and reactive powers $p$ and $q$ are calculated from the transformed voltage and current as given in Eq.(2).

$$
\left[\begin{array}{l}
p=\bar{p}+\bar{p} \\
q=\bar{q}+\bar{q}
\end{array}\right]=\left[\begin{array}{cc}
v_{\alpha} & v_{\beta} \\
-v_{g} & v_{\alpha}
\end{array}\right]\left[\begin{array}{l}
i_{\alpha} \\
i_{\beta}
\end{array}\right]
$$

The compensating reference currents are calculated to compensate the two terms:

1. The oscillating component of the instantaneous active power $(\tilde{p})$

2. The instantaneous reactive power $(q)$

So, the instantaneous active power $(p)$ is filtered by H.P.F to pass only the AC components $(\tilde{p})$ as shown in Fig.3. Then the compensating reference currents are determined by taking the inverse of Eq.(2) as given in Eq.(3).

$$
\left[\begin{array}{l}
i_{c \alpha}^{*} \\
i_{c \beta}^{*}
\end{array}\right]=\frac{1}{v_{\alpha}^{2}+v_{\beta}^{2}}\left[\begin{array}{cc}
v_{\alpha} & -v_{\beta} \\
v_{\beta} & v_{\alpha}
\end{array}\right]\left[\begin{array}{c}
p+p_{l a s s} \\
q
\end{array}\right]
$$

The inverse Park transform is applied to $i_{\mathrm{c} \alpha}{ }^{*}$ and $i_{\mathrm{c} \beta}{ }^{*}$ and this gives the reference compensating currents in standard three-phase form, as shown in Eq.(4).

$$
\left[\begin{array}{l}
i_{c a}^{*} \\
i_{c b}^{*} \\
i_{c c}^{*}
\end{array}\right]=\sqrt{\frac{2}{3}}\left[\begin{array}{cc}
1 & 0 \\
-\frac{1}{2} & \frac{\sqrt{3}}{2} \\
-\frac{1}{2} & -\frac{\sqrt{3}}{2}
\end{array}\right]\left[\begin{array}{l}
i_{c a}^{*} \\
i_{c \beta}^{*}
\end{array}\right]
$$

\subsection{Synchronous Reference Frame}

In this method [9],[10] as shown in Fig.4, the load currents are converted to synchronous $d-q$ coordinates according to park transformation as given below in Eq.(5) 


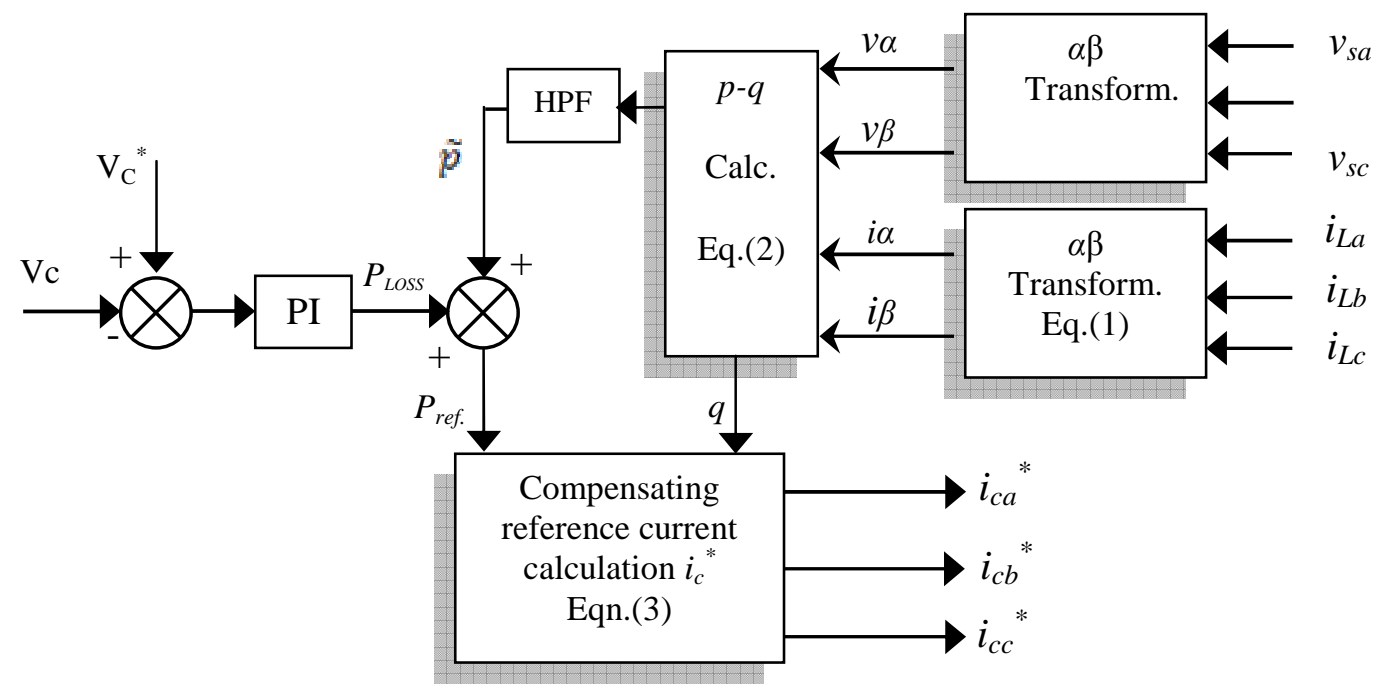

Fig. 3 Block diagram for an active power filter controller using Instantaneous Reactive Power $(p-q)$ Theory

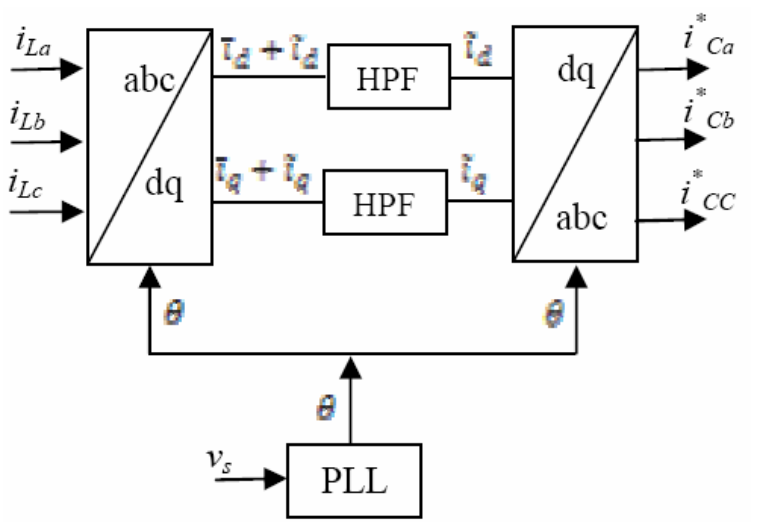

Fig. 4 Principle Synchronous Reference Frame $(d-q)$ method

$$
\left[\begin{array}{l}
i_{d} \\
i_{q}
\end{array}\right]=\frac{2}{3}\left[\begin{array}{ccc}
\cos \theta & \cos \left(\theta-120^{\circ}\right) & \cos \left(\theta+120^{\circ}\right) \\
-\sin \theta & -\sin \left(\theta-120^{\circ}\right) & -\sin \left(\theta+120^{\circ}\right)
\end{array}\right]\left[\begin{array}{l}
i_{i a} \\
i_{i b} \\
i_{i e}
\end{array}\right]
$$

Where $\theta=w t$ is angular position of Synchronous Reference Frame, which is determined by the PLL circuit (Fig.4). Each current component $i_{d}, i_{q}$ that produced from Eq. (5) has an average value or DC component (-) and an oscillating value or AC component as given in Eq.(6)

$$
\begin{aligned}
& i_{d}=\bar{t}_{d}+\tilde{i}_{d} \\
& i_{q}=\bar{i}_{q}+\bar{i}_{q}
\end{aligned}
$$

To get the reference compensating current of shunt APF, the High Pass Filter (HPF) is used to remove the DC component $\left(\bar{l}_{d}, \bar{l}_{q}\right)$ from $i_{d}, i_{q}$. So that, the shunt APF compensate only oscillating value $\tilde{i}_{d} \tilde{i}_{q}$ to cancel harmonics and reactive power compensation. Then, the three reference compensating current of shunt APF can be obtained with an inverse transformation that given in Eq. (5).

\subsection{Shunt Active Filter with Proposed Control Method}

The conventional instantaneous reactive power $(p-q)$ theory is inadequate under non-ideal mains voltage cases [6],[7]. In case unbalanced and distortion mains voltages, the sum of components $v_{\alpha}^{2}+v_{g}^{2}$ will not be constant [8] and oscillating value of instantaneous real power and instantaneous imaginary power are unwanted components of the power system. Consequently, the shunt APF does not generate compensation current equal to current harmonics, and gives to mains more than load harmonics than required. In order to eliminate this drawback and to decrease the total harmonic distortion (THD) to desired level, the new control algorithm is developed. In the proposed method, the fundamental positive sequence detector is added to modify the $p-q$ theory for improving the compensation performance under all voltage conditions. In this new strategy, the shunt active power filter is controlled as it gives the full compensation of harmonics even the mains voltage are distorted and/or unbalanced. In this criteria, the non-ideal mains voltage are converted to ideal case by converted to ideal sinusoidal shape by using the low-pass filter in $d$ - $q$ coordinates. Figure 5 gives a general overview of proposed control strategy to calculate full compensation of shunt active power filter. The principal difference between this proposed control algorithm and the conventional instantaneous reactive power $(p-q)$ theory is the 
addition of the positive-sequence of mains voltage detector as shown in Fig.5.The signal $p_{\text {loss }}$ is used as an average real power and is obtained from the voltage regulator DC-link capacitor voltage is compared by a reference value and the error is processed in a PI controller which is employed for the voltage control loop since it acts in order to zero the steady-state error of the DC-link voltage.

\section{HYSTERESIS BAND CURRENT CONTROLLER}

The actual active power filter line currents are monitored instantaneously, and then compared to the reference currents generated by the control algorithm. In order to get precise instantaneous current control, the current control method must supply quick current controllability, thus quick response. For this reason, hysteresis band current control for active power filter line currents can be implemented to generate the switching pattern the inverter. There are various current control methods proposed for such active power filter [5] but in terms of quick current controllability and easy implementation hysteresis band current control method has the highest rate among other current control methods such as sinusoidal PWM. Hysteresis band current control is the fastest control with minimum hardware and software. But even switching frequency is its main drawback [12]. The hysteresis band current control scheme, used for the control of active power filter line current, is shown in Fig.6,composed of a hysteresis around the reference line current. The reference line current of the active power filter is referred to as ic* and actual line current of the active power filter is referred to as ic. The hysteresis band current controller decides the switching pattern of active power filter. The switching logic is formulated as follows: If ica < ( $\mathrm{i} \square \mathrm{ca}-\mathrm{HB})$ upper switch is OFF and lower switch is ON for leg "a" $(\mathrm{SA}=1)$. If ica $>$ ( $\mathrm{i} \square \mathrm{ca}+\mathrm{HB}$ ) upper switch is $\mathrm{ON}$ and lower switch is OFF for leg "a" $(\mathrm{SA}=0)$. The switching functions SB and SC for phases "b" and "c" are determined similarly, using corresponding reference and measured currents and hysteresis bandwidth (HB).

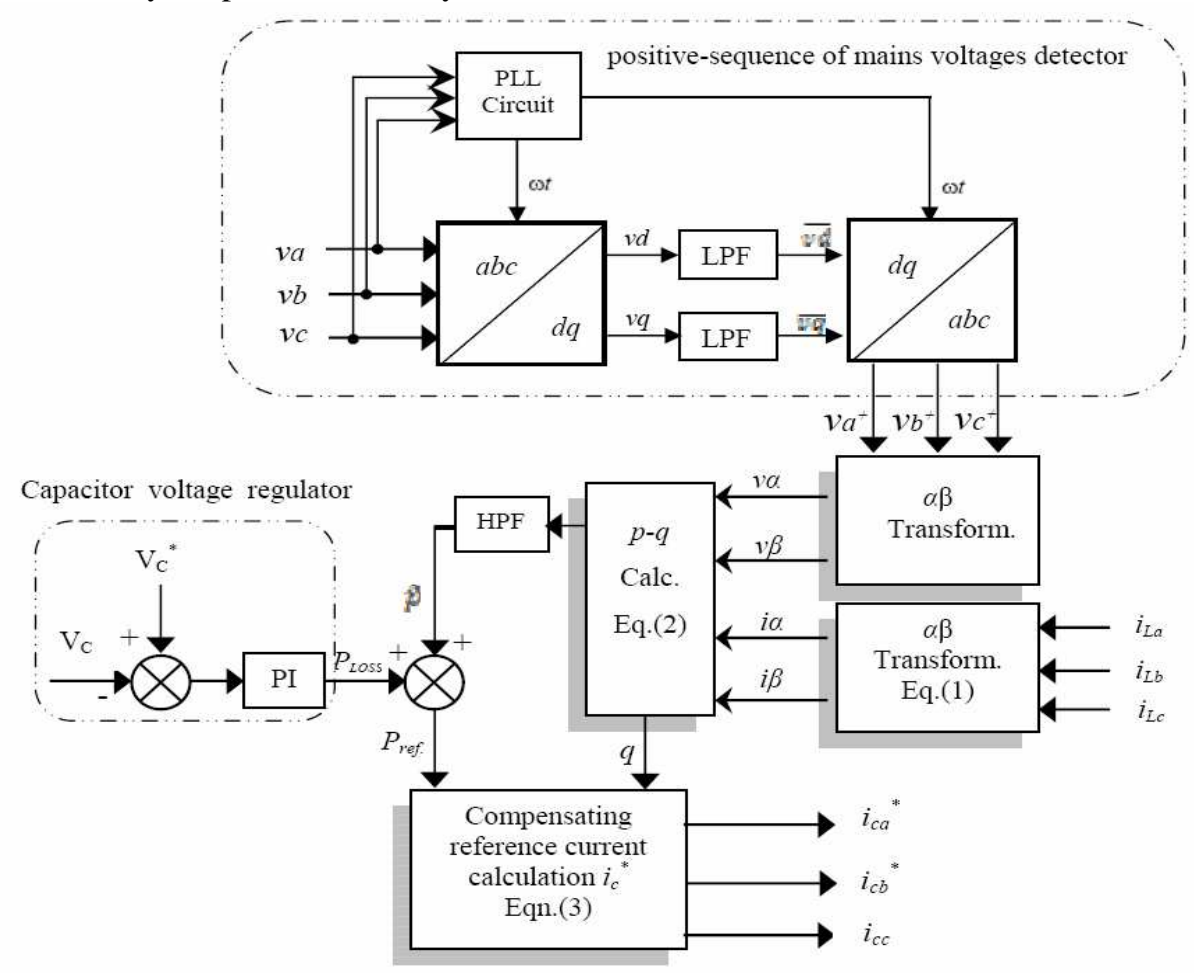

Fig.5 General overview of proposed control strategy

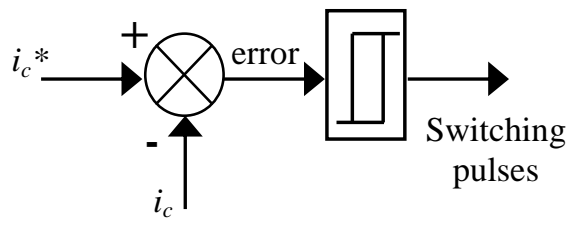

Fig.6 Hysteresis band current controller 


\section{SIMULATION RESULTS}

The purpose of the simulation is to show the effectiveness of the different control strategies for shunt active power filter and in reducing the harmonic pollution produced on the load side under different mains voltage cases, including ideal mains, unbalanced, and distorted voltage. The presented simulation results were obtained by using MatlabSimulink for a 3-phase 3-wire power distribution system with a 3-leg shunt APF and three phase diode bridge rectifier is connected as a nonlinear load. The parameters of this simulated system are reported in appendix (A).

\subsection{Case1: Ideal mains voltage}

Fig.7 shows the simulation results of line current and its spectrum before compensating in case (1) for ideal mains voltage. Figures 8,9 and 10 shows the simulation results with the $p-q$ method, $d-q$ theory and proposed method respectively for the shunt APF under this case of ideal mains voltage. The figures show source current $i_{s}$ after compensating with the supply voltage $v_{s}$ and compensating current $i_{c}$ composed to its reference current $i_{c} *$. Also The spectrum of source current $i_{s}$ after compensating has been cleared. As can be seen from waveforms the source current after compensation became sinusoidal and in phase with three-phase mains voltages. The results in case of balanced main voltages condition using three methods are feasible. Table (1) illustrates the total harmonic distortion (THD) of source current after compensation with shunt APF and power factor value $(P F)$ of each method under ideal main voltages condition. From the figures and table (1) it is observed that, with ideal mains voltage, all the strategies approximately equivalent and able to satisfy the IEEE-519 Standard harmonic current limits [17].

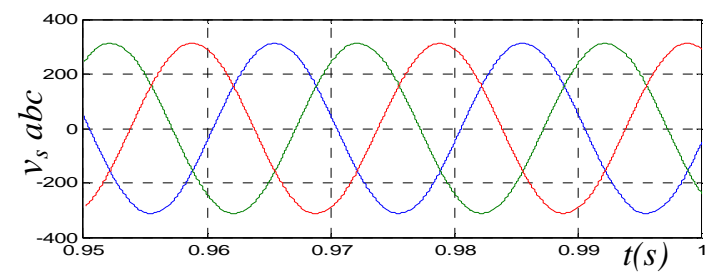

Fig.7-a Three-phase ideal mains voltage

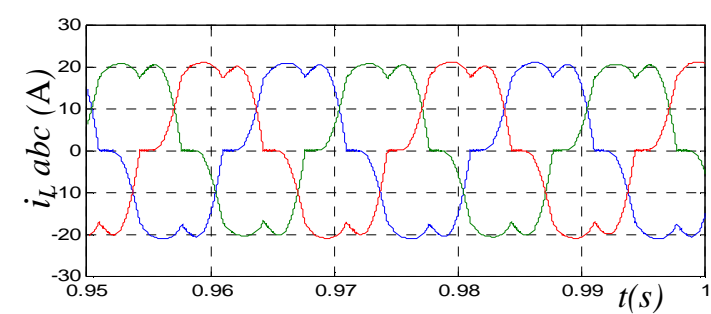

Fig.7-b Three-phase load currents (source currents) before compensating

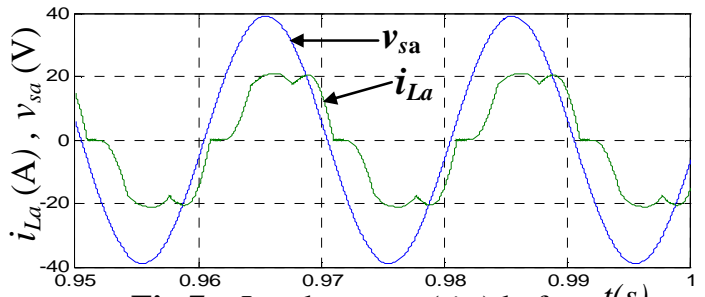

Fig.7-c Load current $\left(i_{L a}\right)$ before $t(s)$ compensating and phase voltage $\left(v_{s a}\right)$

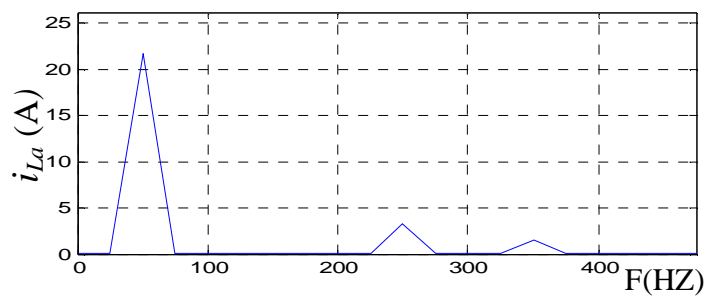

Fig.7-d Spectrum of load current $\left(i_{L a}\right)$ before compensating

Fig.7 Case (1) Ideal (balanced) mains voltage condition
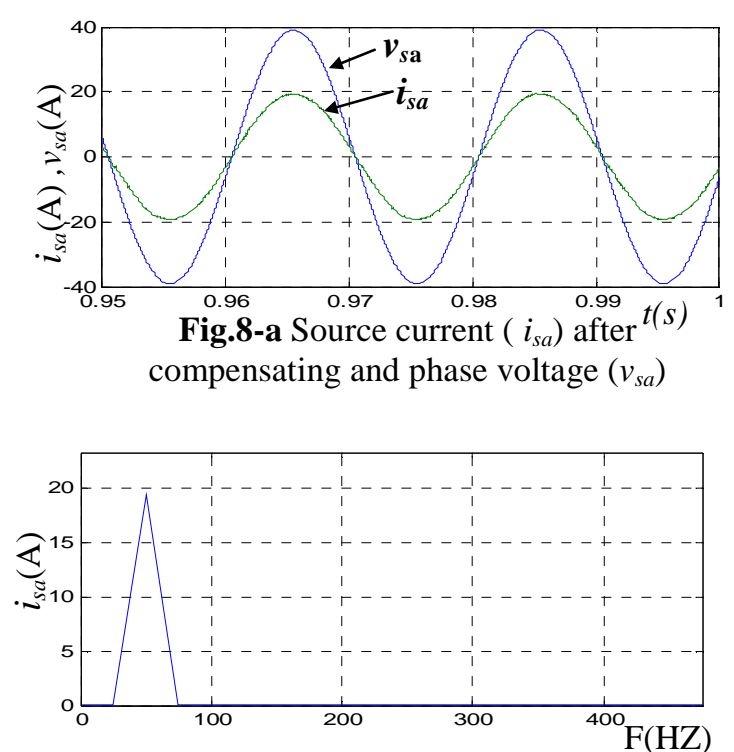

Fig.8-b Spectrum of source current ( $i_{s a}$ ) after compensating

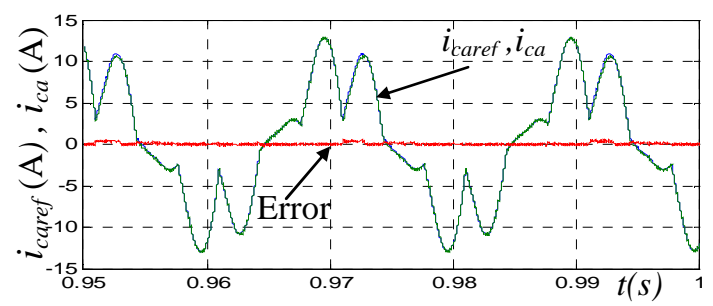

Fig.8-c Compensating current $\left(i_{c a}\right)$ and its reference and error between them

Fig.8 $p$ - $q$ theory performances after compensating in case ideal mains voltage condition 


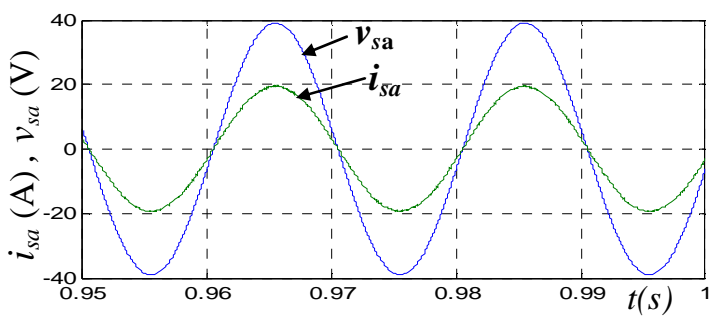

Fig.9-a Source current $\left(i_{s a}\right)$ after compensating and phase voltage $\left(v_{s a}\right)$

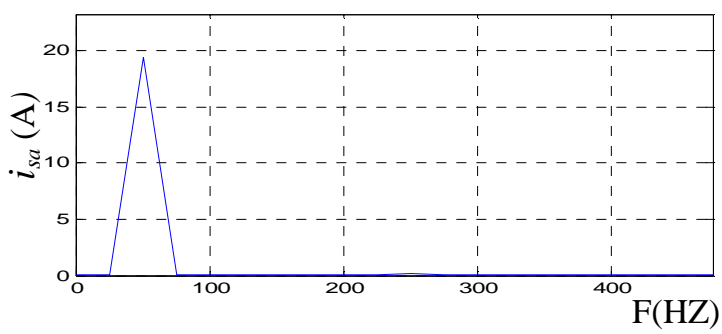

Fig.9-b Spectrum of source current $\left(i_{s a}\right)$ after compensating

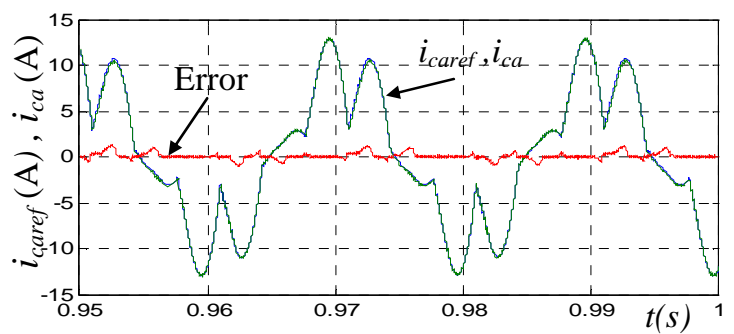

Fig.9-c Compensating current $\left(i_{c a}\right)$ and its reference and error between them

Fig.9 $d-q$ theory performances after compensating in case ideal mains voltage

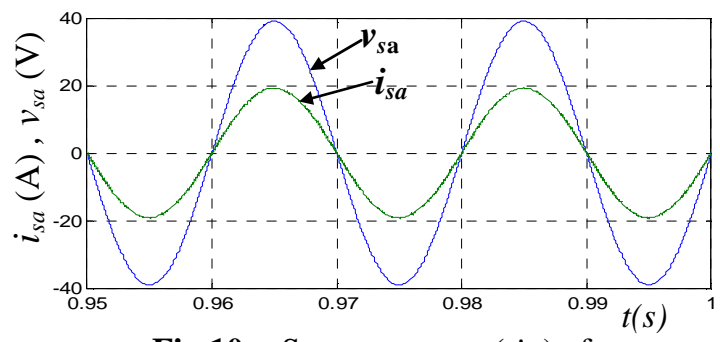

Fig.10-a Source current $\left(i_{s a}\right)$ after compensating and phase voltage $\left(v_{s a}\right)$

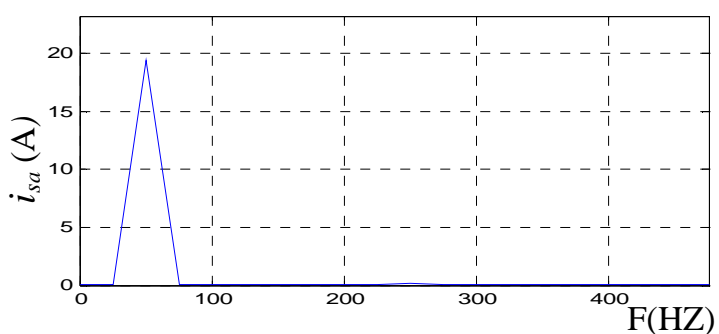

Fig.10-b Spectrum of source current $\left(i_{s a}\right)$ after compensating

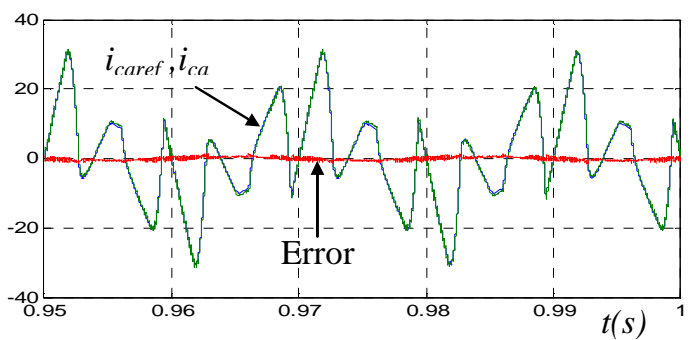

Fig.10-c Compensating current $\left(i_{c a}\right)$ and its reference and error between them

Fig.10 Proposed method simulation results in case ideal mains voltage

Table 1, harmonic content and power factor under ideal mains voltage

\begin{tabular}{|c|l|l|l|l|}
\hline & $\boldsymbol{i}_{\boldsymbol{L}}$ & $\boldsymbol{i}_{\boldsymbol{s} \boldsymbol{p}-\boldsymbol{q}}$ & $\boldsymbol{i}_{\boldsymbol{s} \boldsymbol{d}-\boldsymbol{q}}$ & $\boldsymbol{i}_{\text {s } \text { pro. }}$ \\
\hline $\boldsymbol{T H D \%}$ & 20.88 & 1.825 & 1.527 & 1.013 \\
\hline $\boldsymbol{P F}$ & 0.7871 & 0.9574 & 0.965 & 0.978 \\
\hline
\end{tabular}

\subsection{Case(2): Unbalanced mains voltage}

In this case, the three phase voltages source are unbalanced, where the phase voltages $v_{s a}$ is less than the another phases $\left(v_{s a}=200 \mathrm{r}, v_{s b}=220 \mathrm{r} . \mathrm{m} . \mathrm{s}, v_{s c}\right.$ $=220$ r.m.s) as shown in fig. 11-a. Figures 11-b,c,d show the line current and its spectrum before applied the shunt APF. It can be noted that, the levels of triplens harmonic of source currents spectrum are added before compensation (Fig.11-d) under unbalanced voltages conditions. Figures 12,13,14 show the simulation results with the $p-q$ method, $d-q$ theory and proposed method respectively for the shunt APF under this case of unbalanced mains voltage. where the waveforms depicts the source current $i_{s}$ and its spectrum after compensating, also the compensating current $i_{c}$ with its reference $i_{c} *$ and the error between them are shown in Fig.12-c,d respectively.

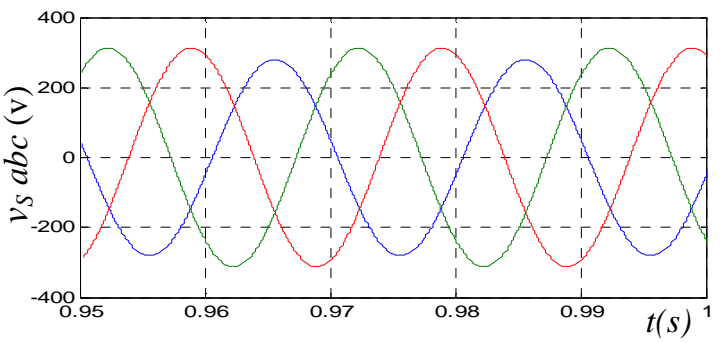

Fig.11-a Three-phase unbalanced mains voltage

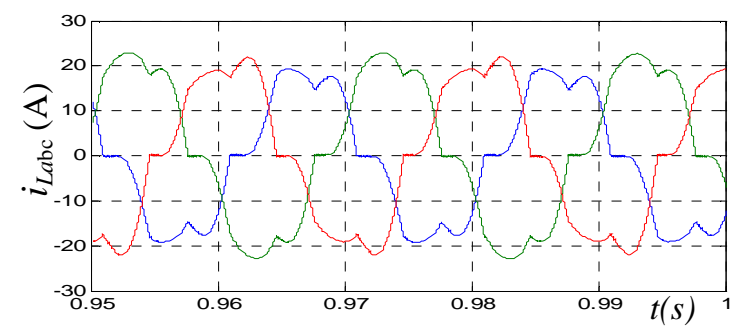

Fig.11-b Three-phase load currents (source currents) before compensating 
E. E. EL-Kholy, A. El-Hefnawy, Hamdy M. Mahrous, " Evaluation of Harmonic Detection Methods for ..."

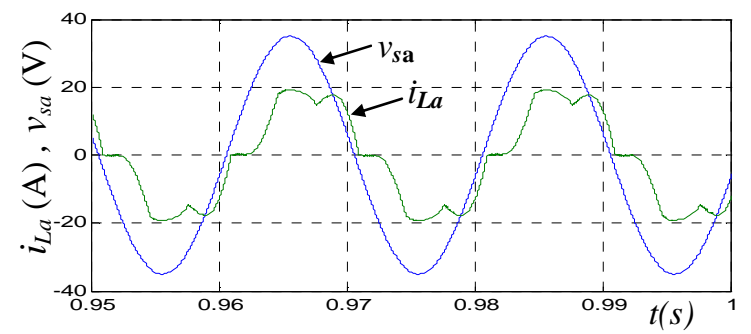

Fig.11-c Load current $\left(i_{L a}\right)$ before compensating and phase voltage $\left(v_{s a}\right)$

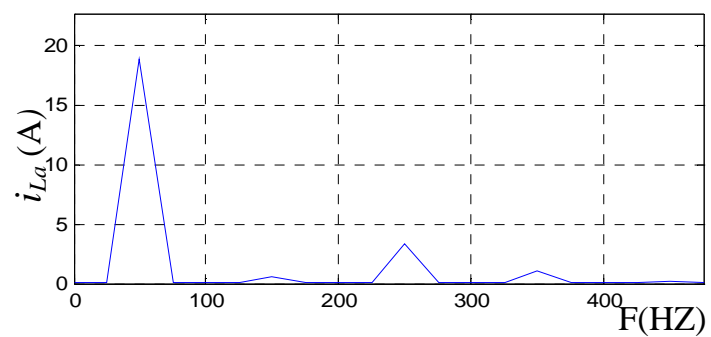

Fig.11-d Spectrum of load current $\left(i_{L a}\right)$ before compensating

Fig.11 Case (2) unbalanced mains voltage condition

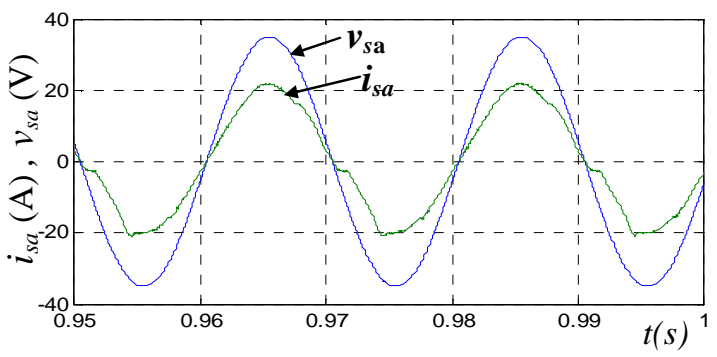

Fig.12-a Source current $\left(i_{s a}\right)$ after compensating and phase voltage $\left(v_{s a}\right)$

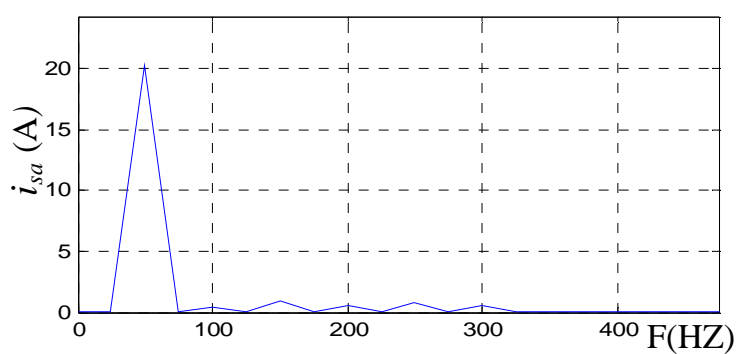

Fig.12-b Spectrum of source current $\left(i_{s a}\right)$ after compensating

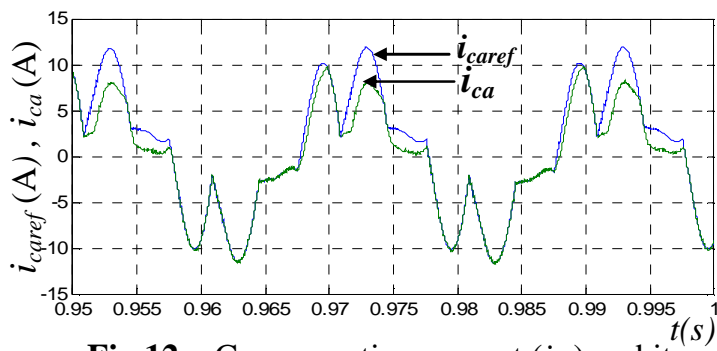

Fig.12-c Compensating current $\left(i_{c a}\right)$ and its reference

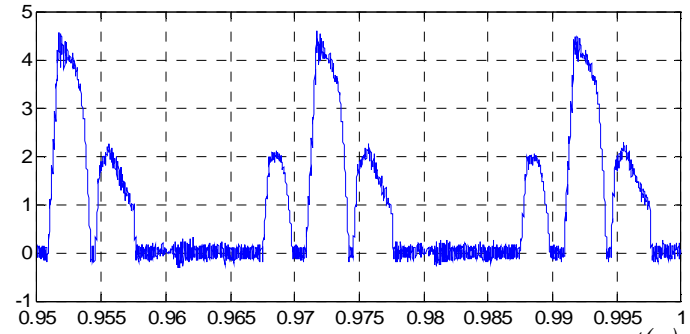

Fig.12-d Error between compensating $t(s)$ current $\left(i_{c a}\right)$ and its reference

Fig.12 $p$ - $q$ theory simulation results in case unbalanced mains voltage condition

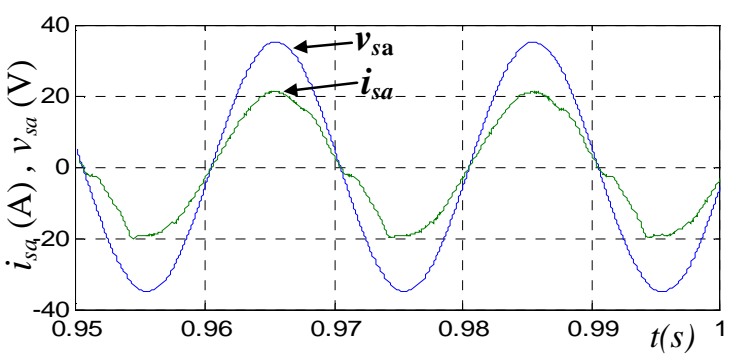

Fig.13-a Source current $\left(i_{s a}\right)$ after compensating and phase voltage $\left(v_{s a}\right)$

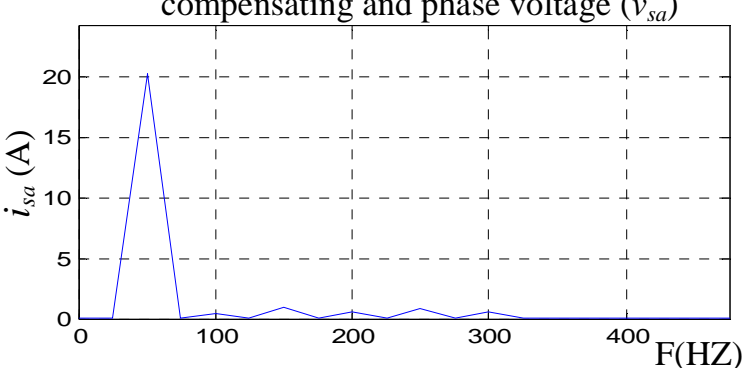

Fig.13-b Spectrum of source current

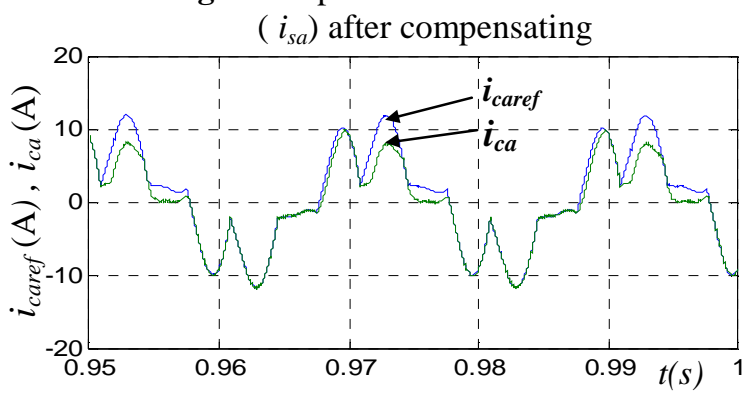

Fig.13-c Compensating current $\left(i_{c a}\right)$ and

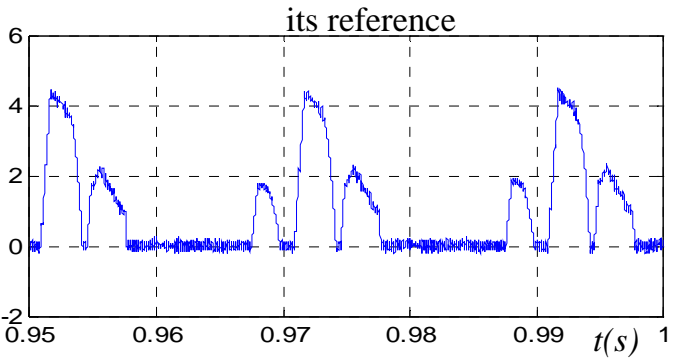

Fig.13-d Error between compensating current $\left(i_{c a}\right)$ and its reference

Fig.13 $d$ - $q$ method simulation results in case unbalanced mains voltage condition 


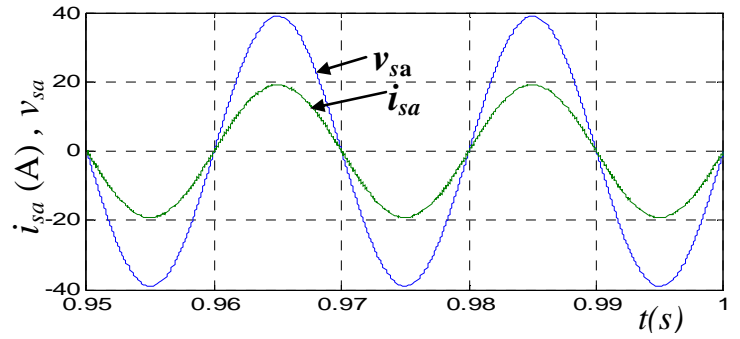

Fig.14-a Source current $\left(i_{s a}\right)$ after compensating and phase voltage $\left(v_{s a}\right)$

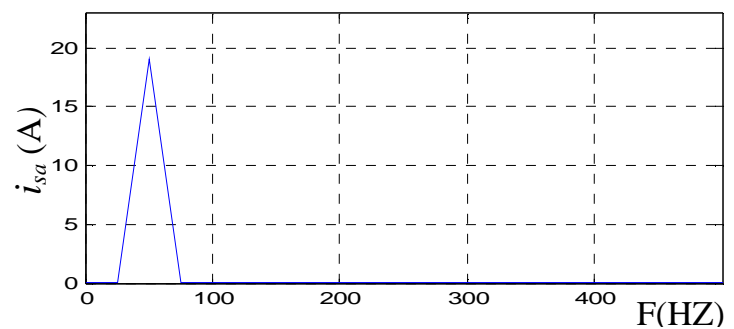

Fig.14-b Spectrum of source current $\left(i_{s a}\right)$ after compensating

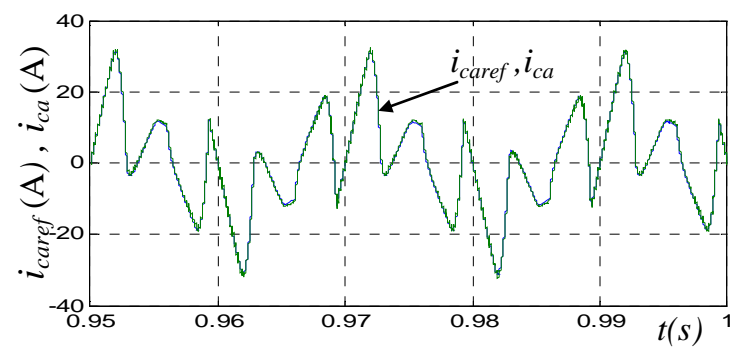

Fig.14-c Compensating current $\left(i_{c a}\right)$ and its reference

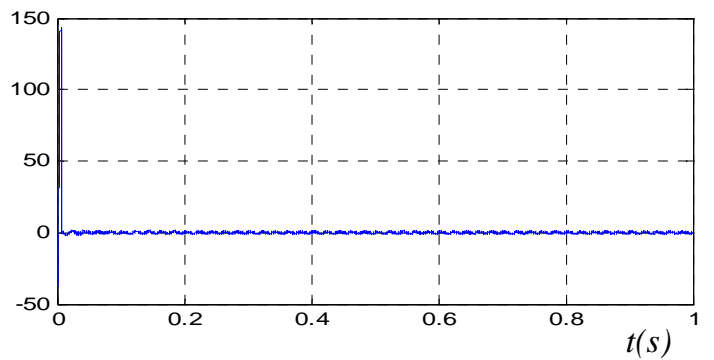

Fig.14-d Error between Compensating current $\left(i_{c a}\right)$ and its reference

Fig.14 proposed method simulation results in case unbalanced mains voltage condition

The harmonic contents reparation, before and after compensation using $p-q$ theory, $d-q$ method and proposed method under unbalanced voltages conditions is resumed in Table (2). It is shown clearly that with comparing the frequency spectra, only the proposed method cancels most of harmonics in the source current but in another methods the source current after compensating is still contain harmonics.
Table 2, harmonic content and power factor under unbalanced mains voltage

\begin{tabular}{|c|c|l|l|l|}
\hline & $i_{L}$ & $i_{s p-q}$ & $i_{s d-q}$ & $i_{\text {s prop }}$ \\
\hline$T H D \%$ & 24.45 & 7.8724 & 7.813 & 1.3 \\
\hline$P F$ & 0.727 & 0.8234 & 0.831 & 0.938 \\
\hline
\end{tabular}

\subsection{Case(3): Distorted balanced mains voltage}

To investigate the system performance under worst conditions of harmonic content, three phase distorted voltages are used in the simulation. Consider the mains voltage have dominant the $5^{\text {th }}$ and $7^{\text {th }}$ harmonic components. For this case, the distorted three-phase main voltages are expressed as Eq.(7)

$$
\begin{aligned}
& v_{a}(t)=V_{1} \sin \omega t-V_{5} \sin 5 \omega t+V_{7} \sin 7 \omega t \\
& v_{b}(t)=V_{1} \sin \left(\omega t-\frac{2 \pi}{3}\right)-V_{5} \sin \left(5 \omega t+\frac{2 \pi}{3}\right)+V_{7} \sin \left(7 \omega t-\frac{2 \pi}{3}\right) \\
& v_{c}(t)=V_{1} \sin \left(\omega t+\frac{2 \pi}{3}\right)-V_{5} \sin \left(5 \omega t-\frac{2 \pi}{3}\right)+V_{7} \sin \left(7 \omega t+\frac{2 \pi}{3}\right)
\end{aligned}
$$

Where $V_{5}=V_{1} / 5$ and $V_{7}=V_{1} / 7$

Figures: 15, 16, 17 and 18 depict simulation results in case distorted mains voltage. It can be seen from these figures that The performance of the $p-q$ algorithm for this case that shown in Fig.16 is not qualified because the supply current after compensating has 17\% THD level. This current after compensation has sinusoidal waveform and improved to $2.3 \%$ THD level for $d-q$ method as shown in Fig.17. In the proposed method (Fig.18), there is more reduction in harmonic distortion level, the supply current after compensating (Fig.18-c) is in phase with positive sequence component of supply voltage $\left(v_{s a}^{+}\right)$therefore, the performance of the proposed method is better than that of the conventional $p-q$ theory and $d-q$ method. Table 3 present summary of simulation results for this case.

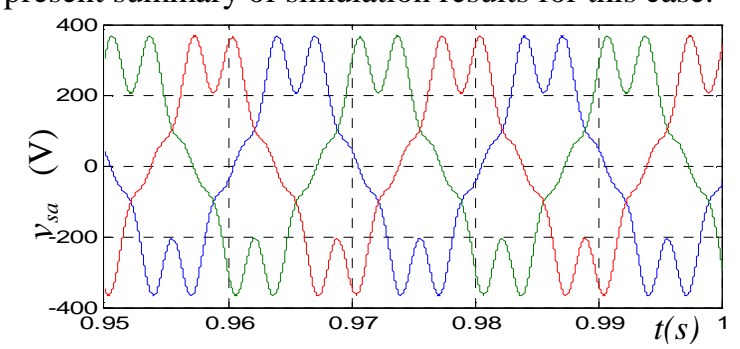

Fig.15-a Three-phase distortion mains voltage

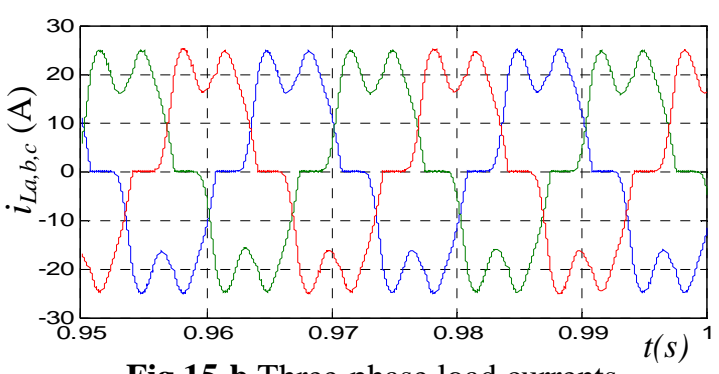

Fig.15-b Three-phase load currents (source currents) before compensating 


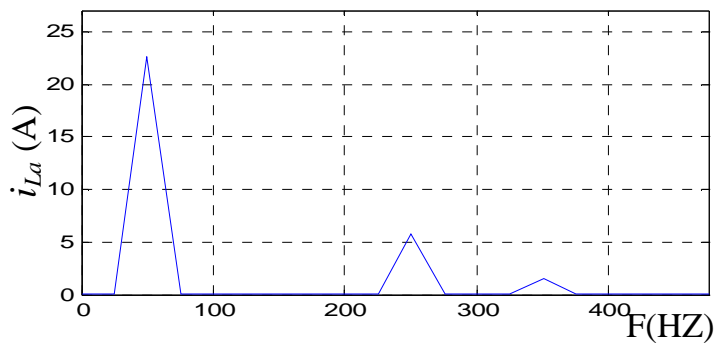

Fig.15-c Spectrum of load current $\left(i_{L a}\right)$ before compensating

Fig.15 Case (3) distortion mains voltage condition

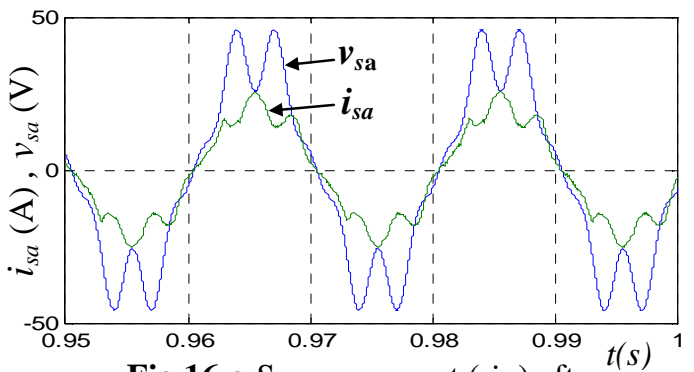

Fig.16-a Source current $\left(i_{s a}\right)$ after compensating and phase voltage $\left(v_{s a}\right)$

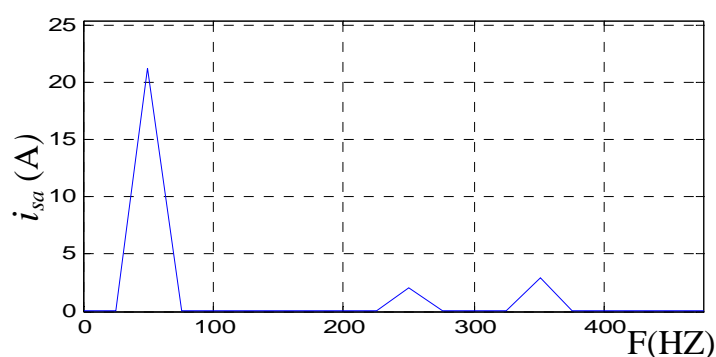

Fig.16-b Spectrum of source current $\left(i_{s a}\right)$ after compensating

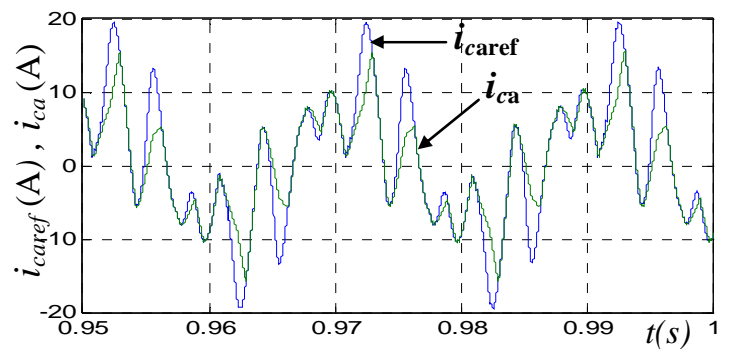

Fig.16-c Compensating current $\left(i_{c a}\right)$ and its reference

Fig.16 $p-q$ theory simulation results in case distortion mains voltage condition

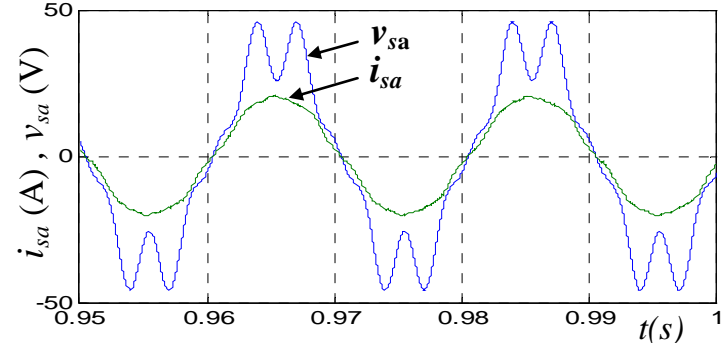

Fig.17-a Source current $\left(i_{s a}\right)$ after compensating and phase voltage $\left(v_{s a}\right)$

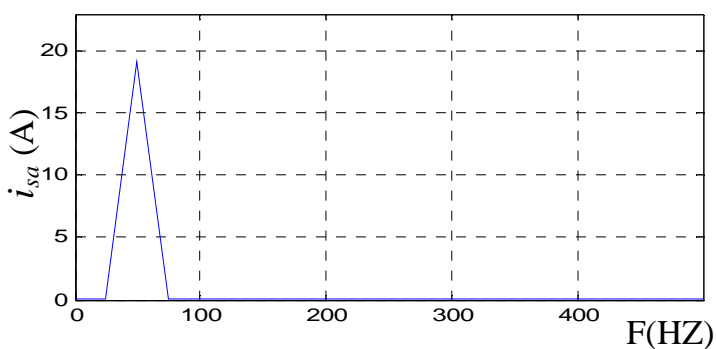

Fig.17-b Spectrum of source current $\left(i_{s a}\right)$ after compensating

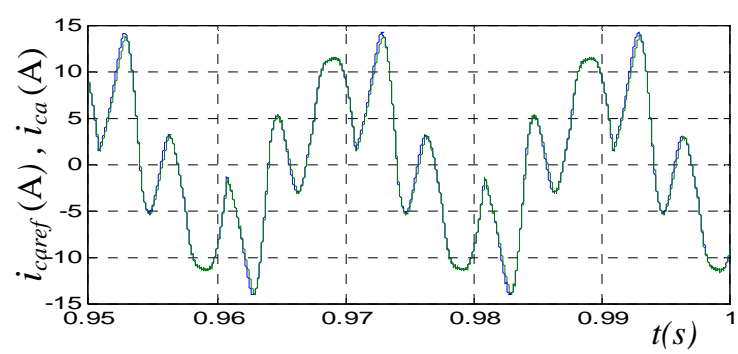

Fig.17-c Compensating current $\left(i_{c a}\right)$ and its reference

Fig.17 $d$ - $q$ method simulation results in case distortion mains voltage condition

Table 3, harmonic content and power factor under distortion mains voltage

\begin{tabular}{|c|l|l|l|l|}
\hline & $i_{L}$ & $i_{s p-q}$ & $i_{s d-q}$ & $i_{\text {s prop }}$ \\
\hline$T H D \%$ & 26.32 & 17.8 & 2.3 & 1.4 \\
\hline$P F$ & 0.727 & 0.7914 & 0.891 & 0.946 \\
\hline
\end{tabular}

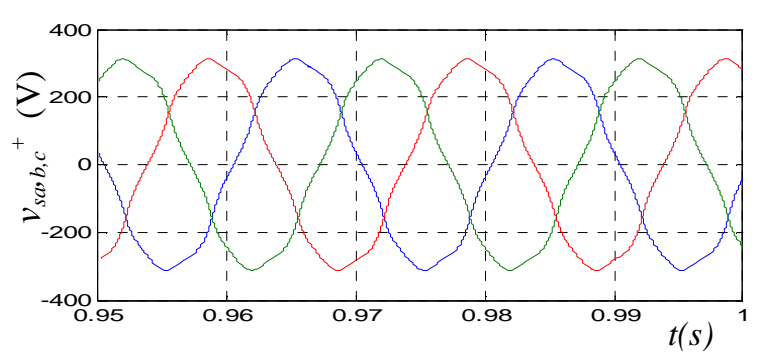

Fig.18-a positive sequence component of mains voltage 


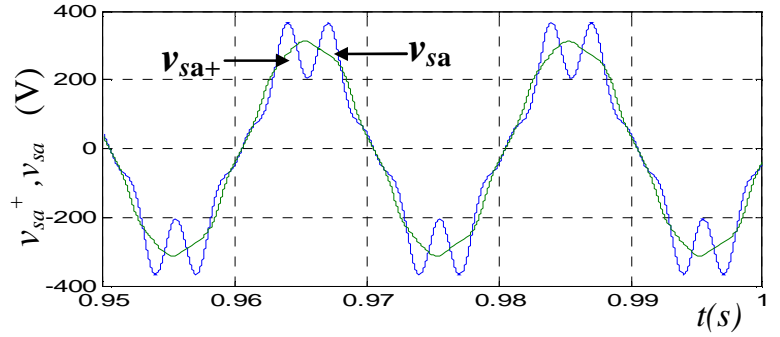

Fig.18-b positive sequence component and its mains voltage

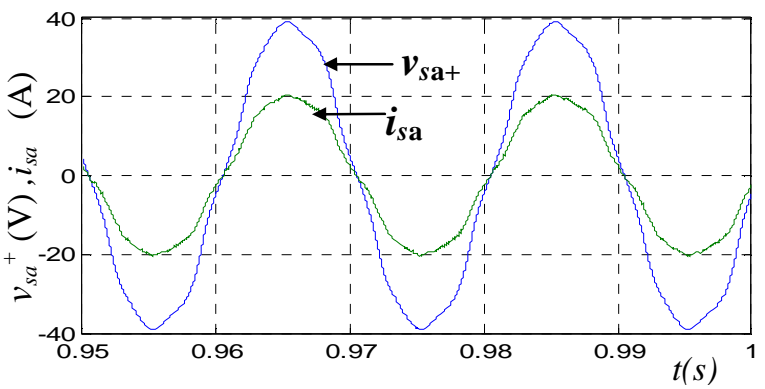

Fig.18-c source current $\left(i_{s}\right)$ after compensating and positive sequence component of mains voltage

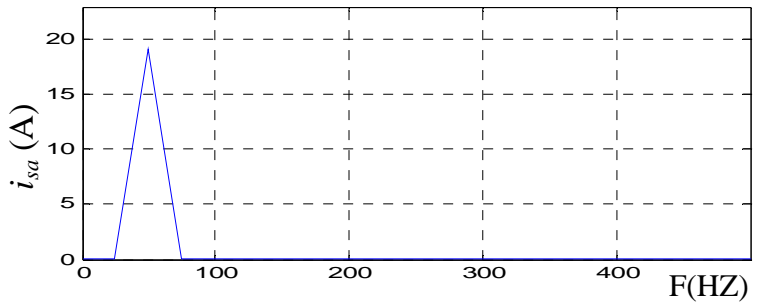

Fig.18-d Spectrum of source current $\left(i_{s a}\right)$ after compensating

Fig.18 proposed method simulation results in case distortion mains voltage condition

\section{EXPERIMENTAL TESTS}

The experimental arrangement has been set up and tested in the laboratory as shown in Fig.19. The three-phase shunt active power filter is achieved with a voltage source inverter (VSI) which contains threephase IGBT. The nonlinear load was a three-phase bridge rectifier with resistive load. The proposed control strategy is implemented using digital signal processor DSP (DS1104) manufactured by DSPACE company and developed under the integrated development environment of MATLAB-SIMULINK provided by the MATHWORK. The supply voltages (vsa,vsb), the load currents (iLa,iLb), the compensating currents of active filter (ica,icb) and dc capacitor voltage of active filter $(\mathrm{Vc})$ are input signal to the DSP board through its ADC interface. The outputs of DSP are gating pulses for the IGBT's of the shunt active power filter through its DAC interface.

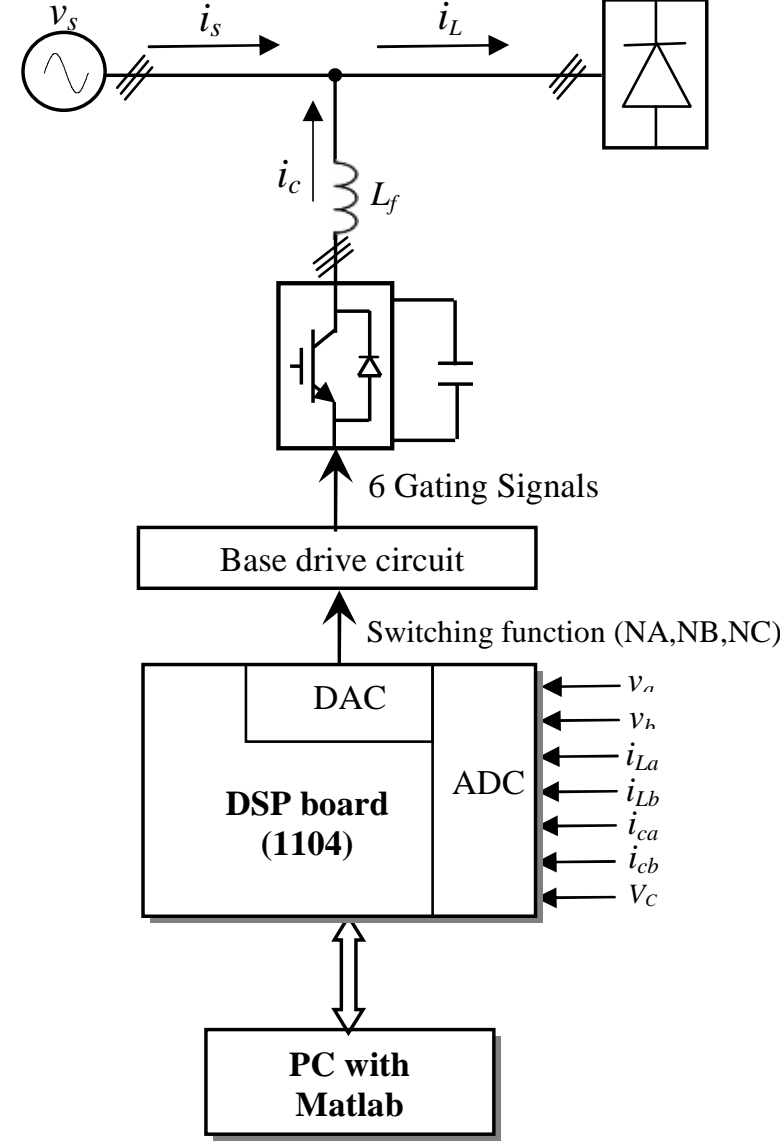

Fig.19 Experimental arrangement setup of shunt APF using DSP

Figure 20 depicts the experimental test results of the prototype for proposed method under a three-phase rectifier load in case of unbalanced and distorted mains voltage. The various waveforms show the positive sequence component of mains voltage in case distortion mains voltage condition (Fig.20-a). Fig.20.b shows the three-phase supply current before applied the shunt active power filter. The supply current after compensating of phase (a) superimposed with fundamental positive-sequence component of the supply voltage is shown in Fig.20-c. The reactive power (Q) before and after compensating is presented in Fig. 20-d where the supply current was found nearly sinusoidal and synchronous with the mains voltage after compensation. It indicates the feasibility of the implemented prototype under this condition. Through experimental results, it is revealed that the supply currents after compensating were found to be sinusoidal and in phase with the fundamental positive-sequence component of the supply voltage, which was consistent with the simulation shown above. For this test, the outcome indicates that the proposed method is useful for the active filter studies and it indicates the effectiveness of the proposed controller for shunt APF under this condition. 


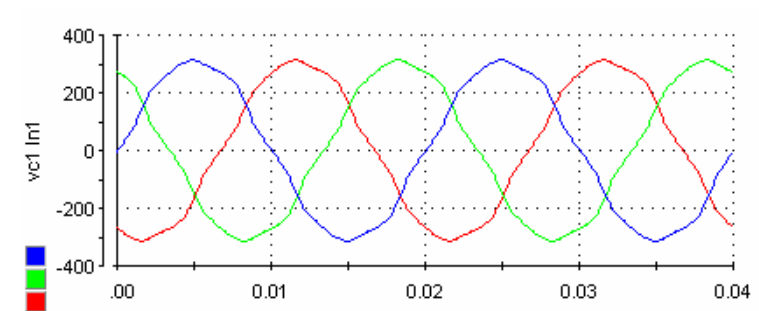

Fig.20-a Experimental result; positive sequence component of mains voltage in case distortion mains voltage condition

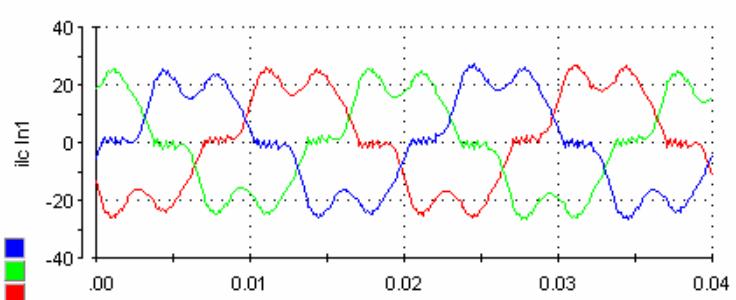

Fig.20-b Experimental result; Three-phase load currents (source currents) before compensating

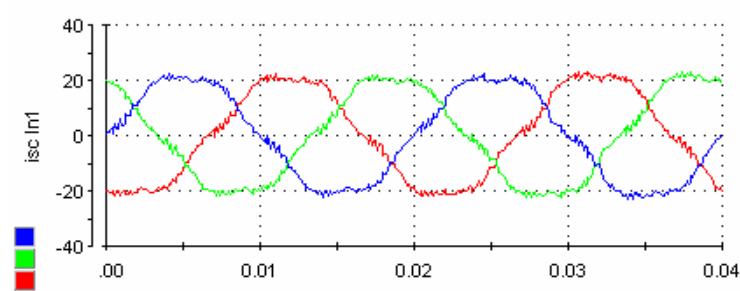

Fig.20-c Experimental result; Three-phase source currents after compensating

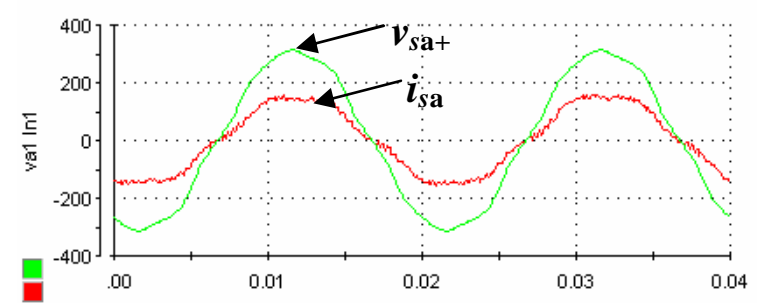

Fig.20-d Experimental result; source currents after compensating and phase voltage

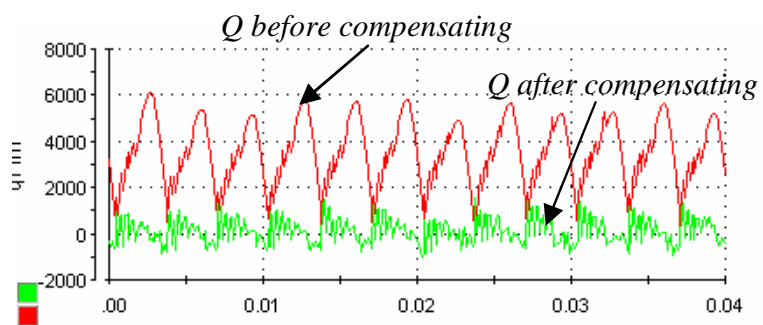

Fig.20-e Experimental result; reactive power (Q) before and after compensating

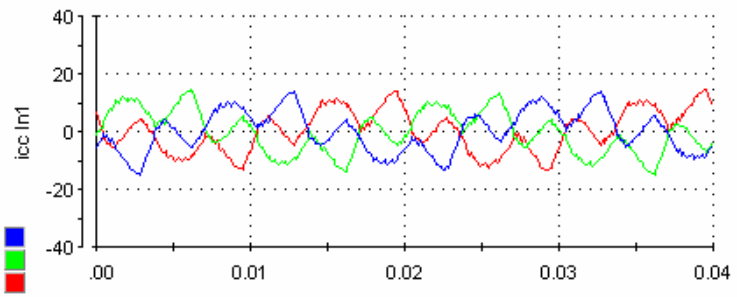

Fig.20-f Experimental result; Three-phase compensating currents

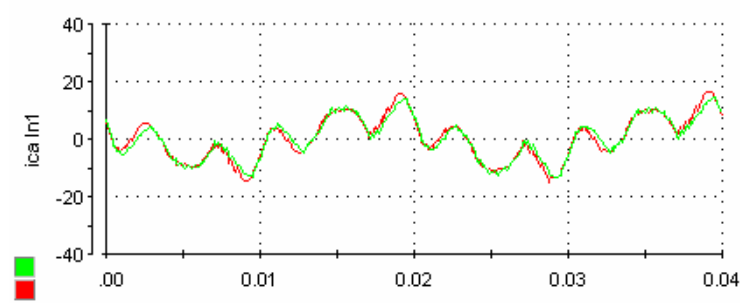

Fig.20-g Compensating current $\left(i_{c a}\right)$ and its reference

\section{CONCLUSION}

A comparative analysis of three control strategies for three-phase shunt APFs has been presented. The comparison has been studied under three cases, including ideal mains voltage, unbalanced threephase mains voltage, and distorted mains voltage conditions. An experimental shunt APF has been carried out on DSP to explore the advantages and practical implementation with the proposed control strategy. The simulations and experimental results have proven good performances and verify the feasibility of the proposed algorithm, and it is most effective for all source voltages conditions. Active power filter, based on the proposed theory, gives satisfactory operation in the harmonic compensation and improving the input power factor even when the system phase voltages are unsymmetrical and distorted.

\section{Appendix A}

\section{The parameters of the SAF}

\begin{tabular}{ll} 
Input voltages & $v_{s}=380$ volt \\
Rectifier load resistance & $R_{d c}=25 \Omega$ \\
Rectifier load current & $i_{L}=20 \mathrm{Amp}$. \\
SAF inductor & $L_{f}=4 \mathrm{mH}$ \\
SAF DC link capacitor & $C=250 \mu \mathrm{F}$ \\
SAF DC link voltage & $V_{c}=750$ volt \\
\hline
\end{tabular}




\section{REFERENCES}

[1] Y. Xu, L. M. Tolbert, J. N. Chiasson, and F. Z. Peng, "Dynamic response of active filter using a generalized nonactive power theory," in Proc. IEEE IAS Annu. Meeting, Oct. 2005, pp. 12251231.

[2] M. Depenbrock, V. Staudt, and H.Wrede, "A theoretical investigation of original and modified instantaneous power theory applied to four-wire systems," IEEE Trans. Ind. Appl., vol. 39, no. 4, pp. 1160-1168,Jul./Aug. 2003.

[3] Y.Xu, L.M. Tolbert, F. Z. Peng, J.N. Chiasson, and J. Chen, "Compensation-based non active power definition," IEEE Power Electron. Lett.,vol. 1, no. 2, pp. 455-450, Jun. 2003.

[4]

[5] M.-R. Rafiei, H. A. Toliyat, R. Ghazi, and T. Gopalarathanam, "An optimal and flexible control strategy for active filtering and power factorcorrection under nonsinusoidal line voltages," IEEE Trans. Power Delivery, vol. 16, no. 2, pp. 297-305, Apr. 2001.

[6] J. Afonso, C. Couto, and J. Martins, "Active filters with control based on the $\mathrm{p}-\mathrm{q}$ theory," IEEE Ind. Electron. Soc. Newslett., pp. 5-11, Sep. 2000.

[7] V. Soares, P. Verdelho, and G. D. Marques, "An instantaneous active and reactive current component method for active filters," IEEE Trans. Power Electron., vol. 15, no. 4, pp. 660669, Jul. 2000.

[8] H. Akagi, S. Ogasawara, and H. Kim, "The theory of instantaneous power in three-phase four-wire systems: a comprehensive approach,"in Proc. IEEE IAS Annu. Meeting, 1999, pp. 431439.

[9] F.-Z. Peng, G.W. Ott, and D. J. Adams, "Harmonic and reactive power compensation based on the generalized instantaneous reactive power theory for three-phase four-wire systems," IEEE Trans. Power Electron., vol. 13, no. 6, pp. 1174-1181, Nov. 1998.
[10] M. Aredes and E. H.Watanabe, "New control algorithms for series and shunt three-phase fourwire active power filters," IEEE Trans. Power Delivery, vol. 11, no. 3, pp. 1649-1656, Jul. 1995.

[11]A. Nabae and T. Tanaka, "Anewdefinition of instantaneous active-reactive current and a power based on instantaneous space vectors onpolar coordinates in three phase circuits," IEEE Trans. Power Delivery,vol. 11, no. 3, pp. 1238-1243, Jul. 1996.

[12]A. Cavallani and G. C. Montarani, "Compensation strategies for shunt active-filter control,” IEEE Trans. Power Electron., vol. 9, no. 6, pp.587-593, Nov. 1994.

[13]H. Akagi, Y. Kanazawa, and A. Nabae, "Instantaneous reactive power compensators comprising switching devices without energy storage components," IEEE Trans. Ind. Appl., vol. IA-20, no. 3, pp. 625-630,May/Jun. 1984.

[14] Ambrish Chandra, Bhim. B.N., Singh and Kamal Al. Haddad "An Improved Control Algorithm of Shunt Active Filter for Voltage Regulation, Harmonic Elimination, Power-Factor Correction, and Balancing of Nonlinear Loads" IEEE Trans on Power electronics. Vol. 15 No3 May 2000.

[15] M. Machmoum and N. Bruyant "Control Methods for Three-Phase Active Power Filters Under Non-Ideal Mains Voltages", Siemens Automotive Moteurs Electriques, Le Présec, IEEE 2000.

[16] Juan W. Dixon, Gustavo Venegas and Luis A. Morán, "A Series Active Power Filter Based on a Sinusoidal Current-Controlled Voltage-Source Inverter", IEEE Transactions on industrial electronics, Vol. 44, No. 5, October 1997.

[17] Seung-Gi Jeong, and Myung-Ho Woo "DSPBased Active Power Filter with Predictive Current Control" IEEE, transactions on industrial electronics, Vol. 44, No. 3, June, 1997. 